\title{
Generalized dynamic model of hydrodynamic vibration dampener subject to viscous damping
}

\author{
Galina Khromova", Malika Makhamadalieva, and Sergey Khromov \\ Tashkent State Transport University, Tashkent, Uzbekistan
}

\begin{abstract}
Use as an elastic body of the working fluid improves the efficiency of the hydraulic damper, reliability, and durability, in this case, the issues of improving the reliability of existing locomotives hydraulic dampers by upgrading separate the components for major repairs with the extension of the useful life are relevant. To increase the efficiency of damping dynamic vibrations and reduce the load on the support units and running gear elements, a modernized design of a hydro friction damper with improved damping properties was developed, for which an application was filed for the Patent of the Republic of Uzbekistan for Invention No. IAP 20210002.
\end{abstract}

\section{Introduction}

In terms of self-financing and connection with the transition to a market economy, one of the most important tasks for our Republic's economic and political independence is to increase freight and passenger traffic, which entails an increase in the fleet of vehicles, including locomotives and high-speed trains. Their use is associated with an application in vehicle suspension systems is complex curved profile and different types of hydraulic dampers and vibration absorbers, which leads to an increase in smoothness of rolling stock and to improve the strength and elastic-dissipative properties of the suspension to reduce the dynamic effects on the path and the transported goods.

Analysis of research on the calculation of hydraulic vibration dampers of vehicles has shown that almost all spring suspension designs of modern electric locomotives, electric trains, metro cars, and trams use hydraulic dampers various types. Hydraulic vibration dampers served as the basis for the creation of new types of adjustable suspensions with automatically controlled parameters speed and high-speed electric rolling stock (for example, in France, Germany, Switzerland, Japan, Spain, China, Russia, and Uzbekistan) [1-3]. To increase the speed of movement and the capacity of railways, it is of great importance to improve the dynamic qualities of electric rolling stock, which depend on the correct choice and stability of the hydraulic vibration dampers and the parameters of the spring suspension. These indicators depend on: the interaction forces between wheel and rail, the stability of the wheels on the rail, and the smooth running locomotive.

*Corresponding author: psion2@mail.ru 


\section{Materials and Methods}

To substantiate the created perspective design of the vibration dampener, a generalized dynamic model of the hydro friction vibration dampener was developed, taking into account the viscous damping [4].

The generalized model under study consists of three coaxially arranged elastic cylindrical shells, one of which is filled with an ideal compressible fluid moving at a constant velocity $V$ and having a pulsating internal pressure (a variable pressure field in time and along the length of the $\left.P_{l}(x, t)\right)[4,5]$.
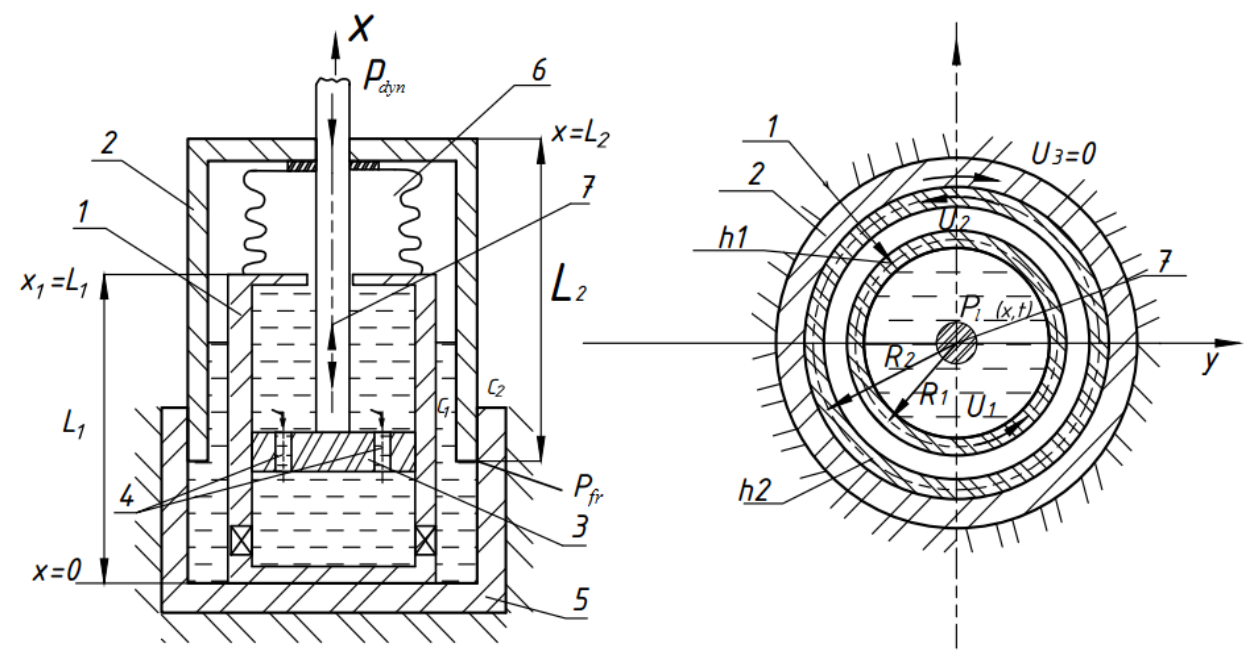

Fig.1. Calculation scheme for modeling the process of dynamic loading of the hydro friction damper of the proposed design [4] and the acting forces, (where it is indicated: 1 is working cylinder, 2 is outer casing (movable), 3 is piston, 4 are throttle channels, 5 is fixed casing part, 6 are bellows, 7 is rod)

Let us turn to the equations of the shell, taking into account the propagation of waves in its material. We take here a variant of the linearized theory of Kirchhoff - shells, considering the deflections of the shells as small $U_{1}, U_{2}, W_{l}, W_{2}$ - in contrast with the thickness of the shell $[6,7]$.

Circular cylindrical shells have external radii $R_{l}, R_{2}$, wall thickness $\mathrm{h}_{1}, \mathrm{~h}_{2}$, length $-L_{1}$, $L_{2}$, elastic pinching act in the inner shell 1 at the ends, pulsating pressure waves in the liquid $R_{j}(x, t)$.

Between the inner shell 2 and the outer shell 3, which is rigidly fixed, there is a friction force expressed by the formula:

$$
P_{f r}(x, t)=f_{f r} \cdot P_{d y n}
$$

There is an external pulsed dynamic load on the outside [8]:

$$
P_{d y n}(x, t)=P_{a} \cdot \cos \omega t
$$

The $O X$ axis is compatible with the longitudinal axis of the shell $L_{l}$. Displacement of the middle surface of the shell 1 in directions forming denote by $U_{l}$, and the displacement of 
the middle surface of the shell 2 is rigidly fixed relative to the outer shell $U_{2}$. Finally, the radial displacement, respectively $-W_{1}, W_{2}[8]$.

\section{Results and Discussion}

Based on the data of $[4,9]$, it is possible to write down the equations of vibrations of two circular cylindrical shells, one of which is filled with a moving compressible liquid with pulsating pressure along the length and time under dynamic impact $P_{d y n}$, in movements:

$$
\begin{aligned}
& \frac{E_{1} h_{1}}{1-\mu^{2}}\left(\frac{\partial^{2} U_{1}}{\partial x^{2}}+\frac{\mu \partial W_{1}}{R_{1} \partial x}\right)+\beta \frac{\partial U_{1}}{\partial t}=\rho_{1} h_{1} \frac{\partial^{2} U_{1}}{\partial t^{2}} \\
& \frac{E_{2} h_{2}}{1-\mu^{2}}\left(\frac{\partial^{2} U_{2}}{\partial x^{2}}+\frac{\mu \partial W_{2}}{R_{2} \partial x}\right)+K_{2} U_{2}=\rho_{2} h_{2} \frac{\partial^{2} U_{2}}{\partial t^{2}}+P_{f r}+P_{d y n}
\end{aligned}
$$

In equations (3), (4), the notation $E_{i}, \mu_{i}, \rho_{i}$ are the modulus of elasticity, the Poisson's coefficient, and the density of the shell material, where $i=1$.

Consider the solution for the system of equations $(3) \div(4)$, taking into account the sequential complication.

The oscillations of the two coaxial shells consider the assumption of small transverse expansion (to be exact $\frac{\partial \boldsymbol{W}_{1}}{\partial \boldsymbol{x}}$ and $\frac{\partial \boldsymbol{W}_{2}}{\partial \boldsymbol{x}}$ tend to 0 ). Taking this into account, the assumed system $(3) \div(4)$ will take the form:

$$
\begin{aligned}
& \frac{E_{1} h_{1}}{1-\mu^{2}} \cdot \frac{\partial^{2} U_{1}}{\partial x^{2}}-\beta \frac{\partial U_{1}}{\partial t}-c_{1} U_{1}=\rho_{1} h_{1} \frac{\partial^{2} U_{1}}{\partial t^{2}}+\bar{f}_{1} \cdot P_{d y n}(x, t) \\
& \frac{E_{2} h_{2}}{1-\mu^{2}} \cdot \frac{\partial^{2} U_{2}}{\partial x^{2}}-c_{2} U_{2}=\rho_{2} h_{2} \frac{\partial^{2} U_{2}}{\partial t^{2}}+\bar{f}_{2} \cdot P_{d y n}(x, t)
\end{aligned}
$$

Divide equations (5) and (6) by $\rho_{l} h_{1}$ and $\rho_{2} h_{2}$ respectively, and transform them by entering the notation:

$$
\begin{aligned}
& \frac{\partial^{2} U_{1}}{\partial t^{2}}-a_{1}^{2} \frac{\partial^{2} U_{1}}{\partial x^{2}}+\bar{\beta}_{2} \frac{\partial U_{1}}{\partial t}+b_{1}^{2} U_{1}=d_{1} P_{d y n}(t) \\
& \frac{\partial^{2} U_{2}}{\partial t^{2}}-a_{2}^{2} \frac{\partial^{2} U_{2}}{\partial x^{2}}+b_{2}^{2} U_{2}=d_{2} P_{d y n}(t)
\end{aligned}
$$

where

$$
\begin{gathered}
a_{1}^{2}=\frac{E_{1} h_{1}}{\left(1-\mu^{2}\right) \rho_{1} h_{1}}=\frac{E_{1}}{\left(1-\mu^{2}\right) \rho_{1}} ; \quad \bar{\beta}=\frac{\beta}{\rho_{1} h_{1}} ; \quad b_{1}^{2}=\frac{c_{1}}{\rho_{1} h_{1}} ; \quad d_{1}=\frac{\bar{f}_{1}}{\rho_{1} h_{1}} ; \\
a_{2}^{2}=\frac{E_{2}}{\left(1-\mu^{2}\right) \rho_{2}} ; \quad b_{2}^{2}=\frac{c_{2}}{\rho_{2} h_{2}} ; \quad d_{2}=\frac{\bar{f}_{2}}{\rho_{2} h_{2}}
\end{gathered}
$$


As a result of solving this equation, using the Fourier method and the Laplace transform, we get $[10,11,12]$ :

for equation (5)

$$
\begin{aligned}
U_{k 1}(t)=\bar{P}_{a 1} & \cdot\left[\frac{\cos \omega_{a} t \cdot\left(p_{3} p_{4}-\omega_{a}^{2}\right)-\omega_{a} \cdot \sin \omega_{a} t \cdot\left(p_{3}+p_{4}\right)}{\left(p_{4}^{2}+\omega_{a}^{2}\right)\left(p_{3}^{2}+\omega_{a}^{2}\right)}+\right. \\
& \left.+\frac{p_{3} e^{p_{3} t} \cdot\left(p_{4}^{2}+\omega_{a}^{2}\right)-p_{4} e^{p_{4} t} \cdot\left(p_{3}^{2}+\omega_{a}^{2}\right)}{\left(p_{4}^{2}+\omega_{a}^{2}\right)\left(p_{3}^{2}+\omega_{a}^{2}\right)\left(p_{3}-p_{4}\right)}\right]
\end{aligned}
$$

similarly for equation (8)

$$
U_{k 2}(t)=\bar{P}_{a 2} \frac{\cos \omega_{a} t-\cos \lambda_{k 2} t}{\lambda_{k 2}^{2}-\omega_{a}^{2}}
$$

The general form of the solution of equations (5) and (6) will be according to the Fourier method [11]:

$$
\begin{aligned}
& U_{k 1}(x, t)=\sum_{k=1}^{N}\left\{U_{k 1}(x) \cdot U_{k 1}(t)\right\} \\
& U_{k 2}(x, t)=\sum_{k=1}^{N}\left\{U_{k 2}(x) \cdot U_{k 2}(t)\right\}
\end{aligned}
$$

Where $k=1,2, \ldots N=5$ is the number of harmonics under vibrations of 2 shells (respectively) under dynamic external loading [13].

The obtained system of equations (7) and (8) takes into account the forces of viscous friction in the details of the proposed damper with the coefficient of energy absorption dynamic loads arising from irregularities in the track [14]. It allows to assess the influence of the geometrical dimensions and parameters of the structure on the parameters of the bodywork of the car electric rolling stock and the details of the damping $[15,16,17]$.

Numerical studies were performed in the Mathcad 15 programming environment and are presented in Figures 2, 3, and 4.

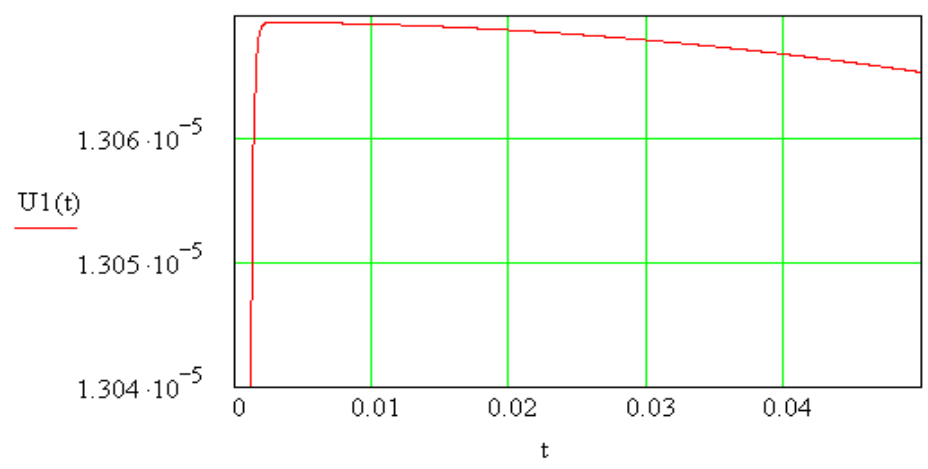

Fig.2. Dynamic displacements of the shell 1, in time $U_{l}(t)$. 


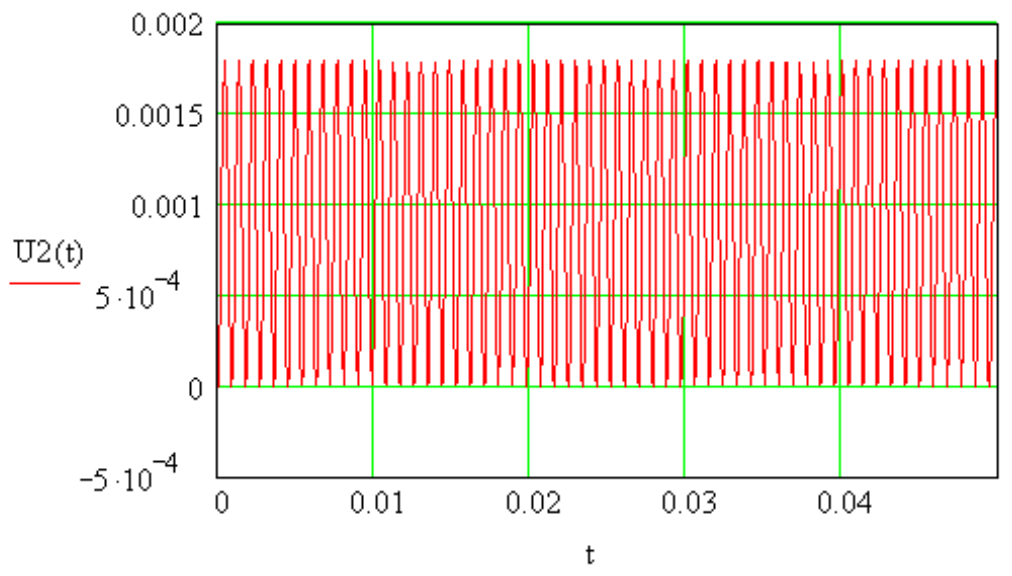

Fig.3. Dynamic displacements of 2 shells in time $U_{2}(t)$.

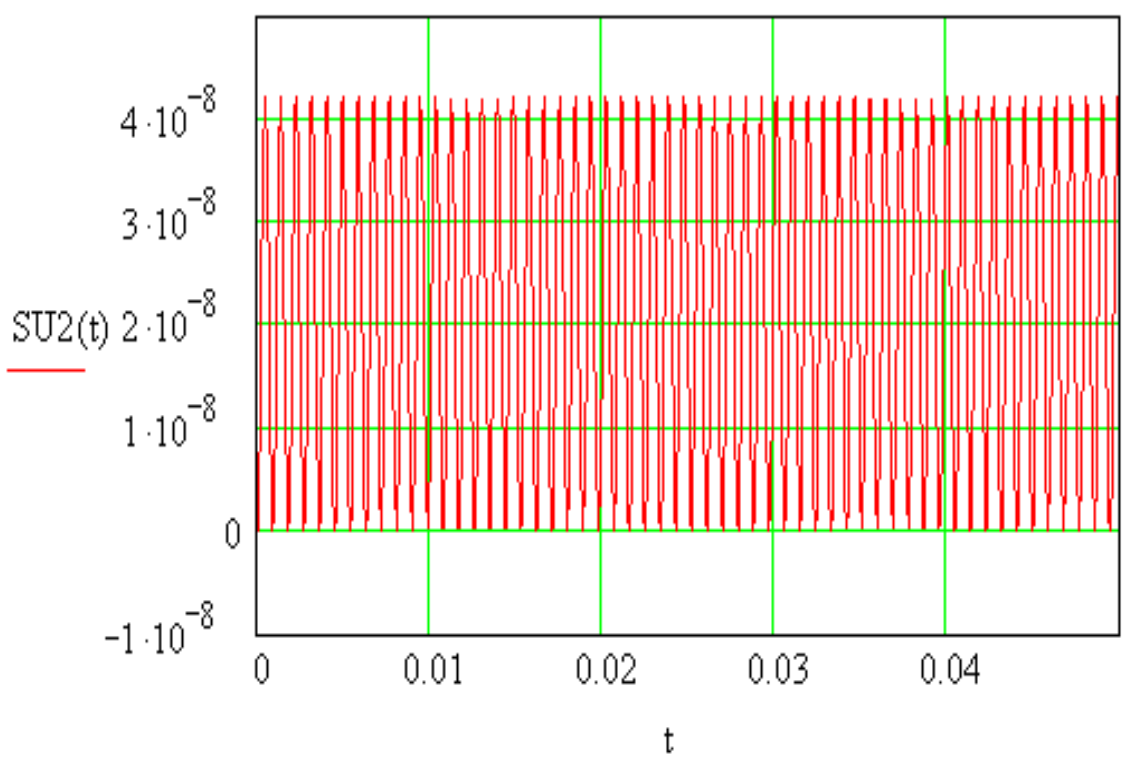

Fig. 4. Total displacements of the second shell of the hydro friction vibration damper in time.

\section{Conclusions}

This mechanical model allows us to describe the dynamic processes occurring in the system and calculate the dampener parameters taking into account the pre-set dynamic characteristics, which are important when calculating and designing new vibration dampeners for rolling stock, as well as when upgrading existing ones $[4,18]$. The resulting mathematical model also allows us to evaluate the influence of structural, power, mass parameters and track irregularities on the process of vibrations of the car body in the 
vertical and longitudinal horizontal planes, as well as the value of the dynamic load of the vibration dampener parts $[19,20]$.

\section{References}

1. Polach O. Creep forces in simulations of traction vehicles running on adhesion limit. Bombardier Transportation, CH-8401 Winterthur, Switzerland Received 13 June 2003; received in revised form 28 November 2003; accepted 1 March 2004. Wear 258. pp. 992 - 1000. (2005),

2. Kamaev V. A. Optimization of Parameters of Running Parts of Railway Rolling Stock [Optimization of Parameters of Running Parts of Railway Rolling Stock]. Moscow. Mechanical Engineering, (1980).

3. Wang W. L., Xu G. X. Fluid formulae for damping changeability conceptual design of railway semi-active hydraulic dampers. International Journal of Non-Linear Mechanics, (44), (7), pp. 809-819. (2009).

4. Khromova G. A., Khromov S. A., Radjibaev D. O., Valiev M. Sh., Kamalov I. S., Makhamadalieva M. A. Torsion-type hydraulic vibration damper [Gidravlicheskiy gasitel kolebaniy torsionnogo tipa]. Application for Patent of the Republic of Uzbekistan for invention No. IAP 2021 0002, filed 05.01.2021.

5. Chelnokov I. I. Hydraulic vibration dampers for passenger cars [Gidravlicheskie gasiteli kolebaniy passazhirskikh vagonov]. Moscow.: Transport, p 73. (1975).

6. Sokolov M. M., Varava V. I., Levit G. M. Rolling stock vibration dampers [Gasiteli kolebaniy podvizhnogo sostava]. Directory. Moscow: Transport, p 216. (1985).

7. Khromova G. A., Makhamadalieva M. A. Mathematical model for dynamic calculation of a hydrofriction vibration damper of an electric rolling stock [Matematicheskaya model dlya dinamicheskogo rascheta gidrofriktsionnogo gasitelya kolebaniy elektropodvizhnogo sostava]. Nauchnyy zhurnal: «Transport shelkovogo puti» (Scientific journal: «Silk road transport»), Tashkent, (2), p 57. (2020).

8. Volmir A. S. Shells in the flow of liquid and gas. Hydroelasticity problems [Obolochki v potoke zhidkosti i gaza. Zadachi gidrouprugosti]. Moscow: Nauka, p 320. (1979).

9. Khromova G. A., Makhamadalieva M. A. Calculation diagram of the hydrodynamic friction support of the flexible shaft of the hydro-friction vibration damper used in railway transport [Raschetnaya skhema opory gidrodinamicheskogo treniya gibkogo vala gidrofriktsionnogo gasitelya kolebaniy primenyaemogo na zheleznodorozhnom transporte]. Nauchnyy zhurnal: «Universum: tekhnicheskie nauki» (Scientific journal: «Universum: Engineering Sciences»), Moscow, (76), pp 77-80. (2020).

10. Svetlitskiy V. A. Mechanics of pipelines and hoses. Problems of the interaction of rods with the flow of liquid and air [Mekhanika truboprovodov $i$ shlangov. Zadachi vzaimodeystviya sterzhney $s$ potokom zhidkosti $i$ vozdukha]. Moscow: Mashinostroenie, p 280. (1982).

11. Anderson R., Elkins J. \& Brickle B. Rail Vehicle Dynamics for the 21st Century. eds. Aref H. \& Phillips J. Mechanics for a New Millennium. Netherlands: Kluwer Academic Publishers, pp. 113-126. (2001)

12. Wang W. L., Zhou Z. R., Yu D. S., Qin Q. H., Iwnicki S. Rail vehicle dynamic response to a nonlinear physical 'in-service' model of its secondary suspension hydraulic dampers. Mechanical Systems and Signal Processing, (95), pp. 138-157. (2017)

13. Jehle G., Fidlin A. Hydrodynamic optimized vibration damper. Journal of Sound and Vibration, 440, pp. 100-112. (2019)

14. Mukhamedova Z., Yakubov M. Methodological aspects of assessment and optimization of the reliability of electrical installations of the railway self-propelled 
rolling stock. International journal of advanced research in science, engineering and technology, January 2019, 6,(1), pp. 7824-7829. (2019).

15. Qobulov J., Barotov J. Method of improvement of efficiency transportation technology. International journal of recent technology and engineering, November 2019, 8, (4), pp. 7720-7726. (2019).

16. Branislav Titurus, Jonathan du Bois, Nick Lieven, Robert Hansford. A method for the identification of hydraulic damper characteristics from steady velocity inputs. Mechanical Systems and Signal Processing, 2010, 24, (8), pp. 2868-2887. (2010).

17. Kim D. H., Park J. W., Lee G. S., Lee K. I. Active impact control system design with a hydraulic damper, Journal of Sound and Vibration, 250, (3), pp. 485-501. (2002).

18. Fayzibaev Sh. S., Khromova G. A., Makhamadalieva M. A. Numerical study of the contact process in the hydro-friction damper for high-speed electric rolling stock. Nauchno-tekhnicheskiy zhurnal «Izvestia Transsiba» (Journal of Transsib Railway Studies), Omsk, Russia, (1), pp. 49-54. (2015).

19. Khromova G. A., Khromov S. A., Rikhsiev K. K. Hydraulic damper [Gidravlicheskiy dempfer]. Patent of the Republic of Uzbekistan for invention No. IAP 04146. Publ. in Bul. (4), April 30, (2010).

20. Khromova G., Mukhamedova Z., Yutkina I. Mathematical model of oscillations of bearing body frame of emergency and repair railcars. International Scientific journal Transport Problems, 12, (1), pp. 93-102. (2017). 